\title{
Keystone Players and Complementors: An Innovation Perspective
}

FRÉDÉRIC MARTY

THIERRY WARIN

\section{S-61 CAHIER SCIENTIFIQUE}




\section{$\checkmark$ CIRANO Knowledge into action}

Center for Interuniversity Research and Analysis on Organizations

The purpose of the Working Papers is to disseminate the results of research conducted by CIRANO research members in order to solicit exchanges and comments. These reports are written in the style of scientific publications. The ideas and opinions expressed in these documents are solely those of the authors.

Les cahiers de la série scientifique visent à rendre accessibles les résultats des recherches effectuées par des chercheurs membres du CIRANO afin de susciter échanges et commentaires. Ces cahiers sont rédigés dans le style des publications scientifiques et n'engagent que leurs auteurs.

CIRANO is a private non-profit organization incorporated under the Quebec Companies Act. Its infrastructure and research activities are funded through fees paid by member organizations, an infrastructure grant from the government of Quebec, and grants and research mandates obtained by its research teams.

Le CIRANO est un organisme sans but lucratif constitué en vertu de la Loi des compagnies du Québec. Le financement de son infrastructure et de ses activités de recherche provient des cotisations de ses organisations-membres, d'une subvention d'infrastructure du gouvernement du Québec, de même que des subventions et mandats obtenus par ses équipes de recherche.

\section{CIRANO Partners - Les partenaires du CIRANO}

Corporate Partners - Partenaires corporatifs

Autorité des marchés financiers

Bank of Canada

Bell Canada

BMO Financial Group

Business Development Bank of Canada

Caisse de dépôt et placement du Québec

Desjardins Group

Énergir

Hydro-Québec

Innovation, Science and Economic Development Canada

Intact Financial Corporation

Manulife Canada

Ministère de l'Économie, de la Science et de l'Innovation

Ministère des finances du Québec

National Bank of Canada

Power Corporation of Canada

PSP Investments

Rio Tinto

Ville de Montréal

Academic Partners - Partenaires universitaires

Concordia University

École de technologie supérieure

École nationale d'administration publique

HEC Montréal

McGill University

National Institute for Scientific Research

Polytechnique Montréal

Université de Montréal

Université de Sherbrooke

Université du Québec

Université du Québec à Montréal

Université Laval

CIRANO collaborates with many centers and university research chairs; list available on its website. Le CIRANO collabore avec de nombreux centres et chaires de recherche universitaires dont on peut consulter la liste sur son site web.

(C) November 2020. Frédéric Marty, Thierry Warin. All rights reserved. Tous droits réservés. Short sections may be quoted without explicit permission, if full credit, including (C) notice, is given to the source. Reproduction partielle permise avec citation du document source, incluant la notice $\mathbb{C}$.

The observations and viewpoints expressed in this publication are the sole responsibility of the authors; they do not necessarily represent the positions of CIRANO or its partners. Les idées et les opinions émises dans cette publication sont sous l'unique responsabilité des auteurs et ne représentent pas nécessairement les positions du CIRANO ou de ses partenaires. 


\title{
Keystone Players and Complementors: An Innovation Perspective *
}

\author{
Frédéric Marty ${ }^{*}$, Thierry Warin
}

\begin{abstract}
Résumé
In this article, we investigate the role of keystone players and consider their impact in terms of innovation rate in an industry. To do so, we build a theoretical framework that considers the innovation rate in the context of an industry with one keystone player and then with multiple keystone players. The results are threefold. First, the presence of a keystone player is incredibly important for innovation on a market. Second, however, our results also show that a biased market power in favor of the keystone player may hinder innovation in this industry, although the negative impact on the industry's innovation rate may not be seen at first. Finally, we demonstrate that an industry obtains a higher innovation rate with multiple keystone players. This framework could inform decisions for the antitrust enforcers.
\end{abstract}

Keywords/Mots-clés: Innovation, Coopetition, Technological Dependence, Dominant Position, Keystone Players, Platform

JEL Codes/Codes JEL: L12, L22, L41, L86

\footnotetext{
* The authors would like to thank CIRANO for its support. The usual caveats apply. Corresponding author: frederic.marty@gredeg.cnrs.fr

${ }^{\dagger}$ Ph.D. CNRS - GREDEG - Université Côte d'Azur \& CIRANO (Montréal)

* Ph.D. HEC Montréal \& CIRANO (Montréal)
} 


\section{Introduction}

This article is about the importance of keystone players for the innovation in an industry. Our first goal is to understand the innovation dynamics in an industry structured in ecosystems, each of them being organized around a keystone player. In order to do so, we build a formal theoretical model to capture these dynamics and propose some new results. Our second and parallel goal is to consider the competition law debates on digital platforms and inform the conversation based on the results we obtain from our theoretical model.

Our main hypothesis is that innovation dynamics on a market organized around a keystone player are of the utmost importance. Indeed, in the specific context of a digital platform, evidence can lead to two different scenarios. First, we may find that a keystone player brings a lot of innovation capacities to an industry. Second, we may also find that a keystone player locks-in innovation alternatives. From a methodological perspective, if we rely on data in a traditional statistical way, we will find evidence of the two scenarios. We propose to consider a Bayesian statistical approach. To us, it depends on the chosen prior. Indeed, depending on this prior, a keystone player may have a positive impact or a negative impact on innovation within an industry. And beyond being just binary, we propose to think with complexity in mind, as the positive impact can be easily visible in the data, while the negative impact can be more subtle.

To better capture the complexity inherent to a Bayesian way of thinking, we propose in this article to built a theoretical framework around an innovation dynamics formal model. We will model an industry constituted of a keystone player and a complementor. We will consider as a prior, the question of the affiliation contract between the keystone player and the complementor. We will consider this prior in two ways: the duration of the affiliation contract and - related to it - the switching costs to another digital platform. ${ }^{1}$

The importance of digital platforms for numerous industries since the early 2000s is not to be demonstrated anymore. In this article, our analytical focus is about innovation dynamics for we want to improve our understanding of the role of digital platforms on markets.

Our reflections are inspired by the idea that firms do not only compete by price, but also by innovation (McIntyre, Srinivasan, and Chintakananda 2020). In the competition law domain, this raises the question about the potential damages to innovation.

While the enforcement of competition rules was exclusively based on the consumer welfare criterion, litigation involving dominant operators in the digital world on both sides of the Atlantic involves the notion of damage to innovation. Such a basis may seem paradoxical given the capacity of digital ecosystems to benefit consumers from countless and constantly renewed innovations. However, the functioning of digital ecosystems is characterized by coopetitive relationships that can have adverse effects on the capacities and incentives of complementors to innovate. The same is true for keystone players about potential intra-ecosystem and inter-ecosystem competition. We show that these two phenomena can slow down the pace of innovation and a distortion of its composition between incremental and complementary innovations.

An important question is the following one: is competition in digital markets becoming less and less intense? This could appear paradoxical in an economy often characterized by the phenomenon of (at least apparent) free access, where firms compete on quality through innovation. The investments of major digital players in research and development, their patent registrations, their efforts to attract the best skills on the labour market, their policies for acquiring start-ups, and their investments as venture capitalists seem to attest to the strategic nature of innovation for these players.

At the same time, however, their market power is criticized as being potentially damaging to innovation. This competitive concern appears mainly in the Investigation of Competition in Digital Markets published in October 2020 by the Antitrust Subcommittee of the U.S. House of Representatives Judiciary Committee (Committee 2020). Indeed, how can we reconcile the hypothesis of a monopolist (or even oligopolist) "quiet life" (Hicks 1935) that would push dominant firms to reduce their pace of innovation with such data? Firstly, the report stresses that the pace of firm creation in the high-tech sector and the initial financing for innovative firms. In a convergent way, the work of Gutiérrez and Philippon (2018) highlights a growing concentration of all sectors of the U.S. economy, including digital, and a rise in mark-ups.

\footnotetext{
${ }^{1}$ This variable will be denoted $\theta$ in our model.
} 
Why would tech start-ups find it more challenging to succeed? The House of Representatives' report provides, in particular, two avenues, which we develop in this article. The first is the kill zones concept. The second is based on firms' ability at the heart of each ecosystem to identify weak signals very early on, if not in near-real time, enabling them to identify competitive risks and opportunities to seize the former and, if necessary, neutralize the latter.

The concept of kill zones was developed in the economic literature by Kamepalli, Rajan, and Zingales (2020). Because of their financial and technical capacities, dominant firms can acquire innovative firms even if they are still potential competitors or develop technologies that may eventually prove to be complementary (not necessarily with a view to a killer acquisition, but also in the perspective of a consolidation in which the purpose of the acquisition is to reinforce the market dominance or to extent this one to an adjacent market). They can also clone products (including improving them) and/or displace the complementor from the ecosystems they dominate, respectively, because of their positions as gatekeepers and regulators. The House of Representatives report shows, through excerpts from hearings before the investigation commission, that many venture capitalists are increasingly reluctant to bet on companies that would be likely to enter such areas. ${ }^{2}$ The innovation strategies may be affected by the anticipation of such competitive risks.

Indeed, as shown by Wen and Zhu (2019) and Zhu and Liu (2018), complementors may prefer to avoid investing in areas that would place them in competition with keystone players. Investments must be complementary to benefit from all the support that the latter can provide to their complementors (Marty, Harnay, and Toledano 2019) but must not lead them to offer services that are or could be substitutable for those developed by each ecosystem's platforms. As one of the people interviewed by the American Parliamentary Investigation Commission noted: "I think Amazon as the sun. It is useful but also dangerous. If you're far enough away you can bask. If you'll get to close you'll get incinerated" (Committee 2020, 49). The additional problem also noted in this hearing is that the distance will also depend on the keystone's future strategy, about which the complementor has no certainty.

The effect is not only significant in terms of incentives to innovate but also in terms of the composition of the innovation. The issue is central according to Ariel Ezrachi and Maurice Stucke. They point out that "under [an] evolutionary perspective, current impediments to innovation can affect not only future levels of innovation but also the types of innovation. Basically, some types of innovation may be lost forever. As a result, today's policy decisions affect not only future levels of investment, but also the paths for innovation and the nature of innovation" (Ezrachi and Stucke 2020).

Two hearings before the investigation commission (as part of the "Innovation and Entrepeneurship" roundtable) may support this hypothesis. The first is that of Fiona Scott-Morton. For the latter, the weakening of competitive pressure from outside the ecosystems allows the keystones to develop a dynamics of innovation going in the direction that is most favourable to them "rather than being creatively spread accross directions chosen by entrants" (Committee 2020, 50). Jason Furman also underlines this control of innovation dynamics: "major platforms have distorted incentives to make more incremental improvements that can be incorporated into the dominant platforms rather than more paradigmatic changes that could challenge these platforms" (Committee 2020, 50).

After the kill zones issue, a second category of factors may explain the ability of large digital ecosystems to (1) identify (at a very early stage) and (2) neutralize competitive threats. Firstly, this is their capacity to control their ecosystem from a technological (by locking in the different stakeholders) and informational (by creating and exploiting an information advantage over them) perspective. ${ }^{3}$. Then, it is about the possibility of using artificial intelligence to identify very quickly and efficiently weak signals about risks or opportunities to predict the immediate future, something more traditional operators cannot do.

\footnotetext{
${ }^{2}$ This is also the case for companies that are competitors of a start-up that has just been acquired by one of the keystone players in the major ecosystems. The takeover bodes well for the acquired firm's performance (or at least the service it was rendering or was likely to render) and for the difficulties of access and market maintenance for its competitors. According to Kamepalli, Rajan, and Zingales (2020), such acquisition results in a $40 \%$ decrease in financing for the firms in the first year following the acquisition. Investor mistrust is compounded by the fact that the number of buyouts in the sector (including by the keystone player) will decline in the future. The hope of a sale gain is, therefore, dwindling.

${ }^{3}$ This is one of the main points in the statement of objections from the DG Competition of the European Commission to Amazon: "Antitrust: Commission sends Statement of Objections to Amazon for the use of non-public independent seller data and opens second investigation into its e-commerce business practices", 10 November 2020, case AT.40462
} 
Our research question is about the impact on the pace and composition of innovation of ecosystems. Our article is structured ariound the following sections. Our next section focuses on the links between digital ecosystems and innovations (both in terms of incentives to innovate and capabilities to innovate). This section shows that a priori, the cooperation model specific to digital ecosystems, can have positive effects in terms of innovations for both the keystone player and its complementors. We qualitfy this effect by taking into account non-cooperative aspects that may alter these effects. Section 3 will look into the literature about increasing returns of being integrated in an ecosystem. Section 4 introduces our hypotheses and our formal model. The development of digital ecosystems does not lead to a depletion of innovation, even if a keystone player tightly controls each ecosystem. Each ecosystem is protected from its competitors by the effects of weak technical inter-operability and strong lock-in effects. This permanence of incentives to innovate arises from the potential threat of other ecosystems, from the risk of disruption by keystone, and above all, from the need to expand its market and access ever more diversified, massive and rapidly renewed data. However, these innovations, which will serve to increase monopoly rents or the effects of lock-ins, lead to an altered innovation in its composition and its pace. A plateau in terms of innovation is theoretically possible. Section 5 discusses the results and will draw the lessons about the means keystone players can create and exploit such lock-in through their investments and their algorithmic advantages. Finally, our last section discusses the competitive or regulatory courses of action to control this possible risk.

\section{Mutli-sided platforms and innovation}

Disputes over major platforms, initiated by the competition authorities, come up against the problematic characterization of consumer welfare damage.

Assessing static and dynamic effects is already the first difficulty. A second, even more apparent difficulty is implementing traditional competition law tools to address anti-competitive practices or to control mergers: the relevant market in the competitive sense of the term is challenging to delimit, and the multifaceted nature of the activities is furthermore reflected in zero price pricing.

Faced with the risks of false negatives that may result, various competitive theories of harm have been proposed. The first of these are damages in terms of quality - for example when practice reduces personal data protection guarantees. The second may be a reduction in the consumer's freedom of choice. Therefore, it is a question of reporting the disappearance of an existing or potential offer on the market. A gradation can then be observed between the European notion of damage to an effective competition and more structuralist notions, which consider the damage to competition results from the reduction of the number of suppliers on the market (competition is here conceived as a situation of effective rivalry between firms on the market).

Two other criteria have been put forward and deserve special attention, especially when combined. These are damage to trading partners on the one hand and damage to innovation on the other. The first criterion may seem contradictory to the current principles of competition law. It would be possible to consider that it is only a vertical issue affecting the sharing of the surplus among firms. However, the consequences of such imbalances may not only be distributional. Imbalances in terms of rent sharing or access to data may reduce innovation and investment capacity, which is ultimately detrimental to the consumer and to the competitive process itself (Bougette, Budzinski, and Marty 2019). The second criterion is damage to innovation. It can be found in European competitive decision-making practice with the Microsoft decision of March 2004 with the notion of damage to subsequent innovation. The control of critical technology for competitors or developers of complementary services or products may allow a dominant operator to hinder their access to the market.

These two criteria can be easily combined and take on a particular meaning in the context of digital ecosystems. An illustration can be found with the three successive Google decisions by the European Commission between 2017 and 2019. For example, the Android decision shows how anti-fragmentation contractual clauses may have hindered the development of alternative mobile ecosystems based on Android forks.

The notions of damage to business partners and damage to third parties to digital ecosystems may seem paradoxical. The latter appears to be a means of encouraging cooperation between firms aimed at developing innovations more quickly. The same case of the Android ecosystem bears witness to this architecture's 
potential effects on innovation, not only that of the keystone player and that of the other players in its ecosystem, e.g. the complementors. Resources are made available to them (data, programming interfaces, computational capabilities, algorithmic services, even direct financial support). Also, the coordination of investments significantly reduces their risks.

However, this perspective on the way these ecosystems function does not display a good understanding of the logic of coopetition. Complementors may constitute a present or future competitive threat to the keystone. ${ }^{4}$ Coopetition and competition are thus intertwined. As shown in the past, the complementor can disrupt the keystone by the case of IBM against Microsoft and Intel. Keystone can enter the complement-market as part of its diversification. The literature produced on the issue of kill zones and killer acquisitions. However, these names are excessive. It is not always a question of suppressing an innovation. These strategies can be "consolidating" in that they aim to increase control over innovations and services to the benefit of the hub. The integration of a technology developed by a complementor (through a merger or acquisition) or the development of an alternative technology can positively affect innovation and consumer welfare.

Ezrachi and Stucke (2020) present some scenarios that could lead to a detrimental innovation strategy in competitive terms. The first scenario is innovation as a barrier to entry: the race to innovate may lead to an increase in rivals' costs, which will be all the less sustainable as the latter do not enjoy the same competitive position, if only in terms of market share. A second scenario returns to the notion of predatory innovation as defined by Schrepel (2018). The innovation eventually produces a gain for the consumer, but is mainly translated into costs for competitors in terms of reduced inter-operability or through the need to revise the specifications of complementary goods and services in a very short time frame. The third scenario is that of cannibalizing innovation. Its effect is to replicate an innovation developed by a third party. The consumer may gain through increased competition, but the strategy has the effect of curbing the growth potential of a company, which may at the same time be hindered in its access to the customer. The fourth type of innovation that can have negative effects on consumer welfare is "exploitative" innovation. New products or services come on the market, but the additional utility for the consumer is paid for by an unjustified increase in data extraction or by manipulative practices or increased possibilities of price discrimination. ${ }^{5}$

In the ecosystem framework, the effects on the capacities and incentives to innovate for all stakeholders (the keystone player and its complementors) must be taken into account. The strategic management literature has already developed numerous works on this cooperation in digital ecosystems (swimming with sharks (Zhu and Liu 2018), dancing with wolves (Lan, Liu, and Dong 2019). Indeed, questions are first raised about the capacity and incentives of complementors to innovate. On the one hand, unbalanced contractual conditions may place them in a situation that makes it impossible to finance investment in innovation. On the other hand, there is also the question of incentives to invest when the prospect of a contractual hold-up could be envisaged. There is a question of participation constraints. Taking these risks into consideration can induce several types of damage to innovation. A first may be damage in terms of composition. The complementor can direct his investments, avoid being squeezed out, in a more favourable direction to the interests of the keystone. One can imagine a reorientation towards incremental instead of radical innovations, but damages may happen through more invisible channels. Innovations that could be developed by complementors could be "reserved" for a dominant ecosystem to the detriment of others. The complementor would then have to pledge cooperation to avoid the risk of being crowded out or absorbed. The bias would then be the consequence of incentives produced by the keystone player (possibly through contractual provisions) towards single-homing.

It is also necessary to consider the situation of the ecosystem's keystone player to consider the effects of this industrial structuring to appreciate its effects on the same incentives to innovate the keystone. Firstly, the literature in strategic management shows that the keystone can be encouraged to clone the innovations of its complements in very particular cases (notably in multi-homing cases or in cases of relative "under-

\footnotetext{
${ }^{4}$ See Visa and Plaid: "In evaluating whether to consider Plaid as a potential acquisition target in March 2019, Visa's Vice President of Corporate Development and Head of Strategic Opportunities expressed concerns to his colleagues about the threat Plaid posed to Visa's established debit business, observing: 'I don't want to be IBM to their Microsoft.'" US DoJ, 5 November 2020, Press Release 20-1204, US v VISA Inc. and Plaid Inc., US District Court Northern District of California, Division of San Francisco, case 3:20-cv- 07810, 5 November 2020.

${ }^{5}$ Investments in pricing algorithms that allow convergence through personalized pricing leading to an increasing share of consumer welfare fall into this category as well as investments in algorithmic tools for manipulating consumers' online behaviours.
} 
performance"). Secondly, "killer" (or rather consolidating) acquisitions can lead to the disappearance of investments oriented towards innovation, not at the level of the prey (i.e. the complementor) but the level of the predator (the keystone in this case). We find here the concept of reverse killer acquisition developed by Caffarra, Crawford, and Valletti (2020).

A final dimension must be considered when analyzing the effects of structuring into ecosystems on innovation dynamics: taking into account inter-platform competition. The primary digital platforms may be strongly dominant in their respective markets, but they compete in their future markets. This is due mainly to convergence phenomena and competition vis-à-vis the platforms' stakeholders (consumers, complementors) and vis-à-vis the complementors themselves. The aim is to solidify its silo by encouraging the various stakeholders to opt for single-homing and make them increasingly captive. Therefore, incentives to innovate remain whatever the relevant market situation could serve as a basis for competitive analysis (social network, the marketplace, mobile operating system). However, let us suppose this molygopolistic configuration explains the current pace of innovation of the major operators (in pure and perfect competition, no capacity to innovate and in monopoly no incentive to do so) (Petit 2020). In that case, questions may arise in the long term about the pace and composition of innovation. Indeed, once the silos have been consolidated, there is a risk that incentives will lead to a slower pace of innovation and to consolidating innovations (diversifying data flows, etc.).

In the following sections, we will see that the pace of innovation for a complementor within an ecosystem, as shown in our modelling, presents a particular profile. A substantial increase, decreasing returns and finally a levelling off and a downward trend while remaining positive.

\section{Increasing returns of integration in an ecosystem}

\subsection{The increasing returns of integration in an ecosystem: coopetition}

A vast literature, particularly in management sciences, analyzes the reasons for cooperation between firms that are keystone to different digital ecosystems and their complementarities (Marty, Harnay, and Toledano 2019; Marty and Warin 2020).

In financial and technical terms, the cooperation has many advantages for both the complementors and the keystone. For the former, as shown by the European Commission's Android decision, the affiliation contract gives them access to APIs, data sets to train their algorithms and target their developments, and algorithmic and computational capabilities made available by the keystone. This cooperation results in benefits such as lowering barriers to entry and the accelerated benefit of network effects etc. The Android decision also shows that the hub is of immediate interest. It benefits from the skills and investments of its complementors. It diversifies risks. It increases its attractiveness to users on the other side of the market. Android's success story (a virtuous circle linked to cross externalities between the two sides) contrasts with the case of Windows Phone, with externalities playing in the opposite direction.

It should be noted that this model is not conceivable outside such ecosystems, in other words, within traditional markets. Firstly, digital ecosystems allow for the minimization of transaction costs (Coase 1937) and the implementation of long-term contracts (Williamson 1985) favouring long-term specific investments. Beyond these neo-institutionalist arguments, it is also possible to highlight neo-Austrian logics (Gaffard and Quéré 2007). Platforms make it possible to coordinate firms' investments on a basis other than that of price signals by also securing investments over sufficient time horizons. Indeed, the concentration of economic power gives the keystone of each ecosystem a coordinating power vis-à-vis the other members of the ecosystem. The keystone position gives it the ability to set prices and contractual terms as well as to determine the economic activity structure and the innovation dynamics. Paul (2020) states that economic power gives "rights of coordination" that would be sanctioned by competition rules in other market configurations. The result is a market model that is quite far removed from traditional Industrial Organization approaches: technologies do not pre-exist at the time of the investment decision, adjustments are anything but instantaneous, data are co-produced by stakeholders and profitability strategies are established over the very long term, etc.

The construction of such favourable ecosystem externalities presupposes that the keystone makes a set of 
trade-offs favourable to the complementors. Williamson and De Meyer (2012) (p. 33) list some of these conditions: (1) attribute the added value to the complementor that generates it, (2) build and structure complementarities between ecosystem members, (3) stimulate complementary investments, (4) reduce transaction costs, (5) promote flexibility and develop shared learning and (6) design value capture tools for all. The case of the Android ecosystem litigation can show that the hub strategy can evolve depending on the competitive pressure on its ecosystem and its value capture strategy.

\subsection{The increasing returns of integration in an ecosystem: competition}

However, the literature in management sciences shows that relationships within ecosystems can be characterized by non-cooperative strategies over the long term, which are all the easier to implement when the partners act in a situation of imperfect information and when dependency relationships increase over time. The reasons are at once because of asymmetries in the control of information, the technological dynamics of ecosystems and in the realization of specific investments whose value will depend solely on the unilateral decisions of the keystone.

First of all, it is a question of considering the increasing dependence of the complementors. As evidenced by the literature on corporate partnerships, cooperative models show that the alignment of interests is not without ulterior motives and antagonisms between firms: it may be a place of both moral hazard and significant contractual imbalances. It is necessary to bring in the temporal dimension and the specificity of investments (complementarity and lock-in effects). For the complementors, this leads to situations of increasing economic and technological dependence as the relationship develops (Committee 2020).

The next step is to consider the possible contractual opportunism of the keystone player. Complementors may fear a non-cooperative strategy of the keystone under certain conditions (Zhu and Liu 2018). What are the keystone's incentives to end cooperation? It is only in the interest of developing breakthrough innovations in competition with other ecosystems (Petit 2020). Conversely, strategic innovations from an intra-ecosystem perspective consolidate its position vis-à-vis the various stakeholders (users, complementors, etc.). These are innovations that bring into play complementarities (access to other data sources) and incentives that reinforce the effects of lock-in: both concerning users but also for complementors. They are all the more vulnerable as they evolve in a situation of economic and technological dependence (Bougette, Budzinski, and Marty 2019).

The risk is not only that of eliminating competitive threats, present or future. It lies not only in strategies to suppress innovation, but more often in strategies to control technological dynamics and consolidate the keystone position. These advanced threats and opportunity detection capabilities are based on nowcasting prediction capabilities that we will detail below, based on informational, algorithmic and computational advantages. Neutralization capabilities, supported by financial resources that transform keystone players into venture capitalists, make it possible to target nascent competitors and control competitive dynamics (Hemphill and $\mathrm{Wu} 2020$ ).

\subsection{Which exit option?}

The stakes for the keystone vis-à-vis the complementors are the same as for the users, to push them to singlehoming and make them captive. This reduces inter-platform competition and creates a profitable asymmetry in intra-platform relationships. For complementors, the situation can also be approached with the contract economics literature: their investments are now only specific investments that lose all value within the ecosystem. The longer the relationship, the more oligopolies the market faces between a few vertically integrated silos, the fewer the exit options. The complementor is gradually trapped in an ecosystem because its exit option is increasingly expensive. Not only does it lose the value of its specific investments, but because of the contractual clauses, it may lose access to strategic assets, data, ${ }^{6}$ but also it has fewer available alternative platforms - it will not be able to bargain a good position. The exit effect is not too significant for the keystone, but the risks are high for the complementors.

\footnotetext{
${ }^{6}$ Cf. Amazon's contractual clauses but the dependency is also technical (on the same case, see the consequences of the loss of access to AWS on data storage, processing etc.
} 


\subsection{A plateauing innovation pace?}

Two dimensions have to be considered successively: both players in an intra-platform cooperation logic (a and b) then the impact on the balance of inter-platform competition (c).

Our theoretical framework is based on Aghion et al. (2005)'s work, also presented in Marty and Warin (2020), and Ezrachi and Stucke (2020). It is based on an innovation intensity in the form of an inverted U-shaped curve. In pure and perfect competition, the incentives to innovate are strong, but the capacity to do so is weak. In a monopoly, the incentives are weak even if the capacity to finance innovation is significant. There is, therefore, a maximum innovation intensity for an oligopolistic competition. As soon as the competition becomes too imperfect, the innovation intensity decreases. Such a scenario could prevail if the market is structured in silos and inter-ecosystem competition becomes weaker.

However, innovation can experience a plateau rather than a decline. This is the first hypothesis that we will analyze. Indeed, competition between ecosystems persists (Petit 2020), and keystone players need renewing, and increasingly diversified data flows. The second hypothesis does not concern the pace of innovation but its composition. The keystone can orient the innovation dynamics of its ecosystem to its benefit. ${ }^{7}$ As Ezrachi and Stucke (2020, p. 41) note:

"Innovation can continue to occur in heavily concentrated markets, but the nature of innovation might change. For example, rather than breakthrough innovations, the innovations might be largely incremental and complementary to the dominant platform's technology and services (such as developing apps for a mobile operating system). Open systems, relying on user-driven innovations, might slowly close after a few firms dominate the industry".

If the keystone player can facilitate the adoption of innovations by leveraging scale effects and ensuring compatibility within the ecosystem, it can filter the innovations that reach the market.

- Capping of incentives to innovate for the complementor

The result is a specific innovation dynamics that is described by the formal model. The innovation rate is gradually depleted with the duration of integration into the ecosystem. For the complementor, this may be due to the following factors: (1) expropriation of the rent due to dependence and therefore less capacity to invest, (2) confinement to incremental innovations limiting the incentives to invest (lower potential gains than it can be expected for radical innovations).

- Capping of incentives to innovate for the keystone player

A similar reasoning can be made on the keystone side: there is no incentive to invest to "replace" oneself. However, the pace of innovation is not going towards zero: maintaining an ecosystem of complementors, the necessary capture of user data, etc., and competition between platforms. So there is a preservation of innovation, but a reduction in its pace and a possible alteration of its composition. Following Ezrachi and Stucke (2020, p. 52), it should also be noted that the persistence of the keystone player's incentives to innovate may be biased in favour of defensive innovations that may have ambiguous effects, to say the least, on consumer welfare and on the competition process itself.

- What are the consequences of cross-platform competition on the positions of the curve?

The presence of ongoing competition in the current, future or potential markets of the keystone player may have the effect of preserving incentives for innovation and thus maintain it at a higher level, but should not alter our assumptions as to the shape of the innovation dynamics. This is indeed what we test in our model.

\section{The model}

Indeed, as aforementioned we have two scenarios in the literature: one that demonstrates that keystone players are important innovation enhancers, and another one that demonstrates with force evidence that

\footnotetext{
${ }^{7}$ As Ezrachi and Stucke (2020) note, this questioning can also prevail in the analysis of the contestability of markets. Not only can the flow of inputs be reduced, but the possibility of successful and independent inputs can be degraded.
} 
keystone players can be a threat to innovation dynamics. Clearly, innovation dynamics on a market organized around a keystone player are of the utmost importance. Conventional statistical evidence can tell two stories. This is where complexity thinking and Bayesian principles have to be considered. To this goal, we propose to build a theoretical framework around an innovation dynamics formal model.

In what follows, we model an industry constituted of a keystone player and a complementor.

Our prior is the question of the affiliation contract between the keystone player and the complementor. We consider this prior, denoted, in two different ways: the duration of the affiliation contract and - related to it - the switching costs to another digital platform.

\subsection{Innovation with only one platform}

Horowitz and Lai (1996) designed a very elegant model to represent the innovation dynamics in an industry with an innovator and an imitator. The goal of their model was to find the effect of patenting on innovation. Their model helped them define two interesting measures: the size and the frequency of innovation in order to characterize the innovation dynamics. In what follows, we will use the same concepts. Also, their model allows them to also determine the optimal patent length to obtain the higher innovation rate. The latter point is what motivated us to rely on this model.

Inspired by their discussion, we think we can make two adjustments to their original model; (1) we can apply it to a slightly different research question and (2) we can extend it to the question of keystone players.

We will apply the original model to compute the innovation rate in an industry where there is a keystone player, which is also a platform, and a complementor.

Hypothesis 1: keystone players provide a boost in innovation in an industry by offering a general-purpose technology to its complementors.

Let us build on this hypothesis and design some of the optimization constraints.

First, the platform has all the power in terms of the affiliation contract terms with its complementor. The platform accepts or rejects a complementor whenever it wants.

Second, the complementor will sign the terms and during this period, it will use the platform's technology. As a consequence, it will not seek to innovate itself and potentially develop a competitive service.

Third, when a complementor leaves a platform, then it can and must innovate to meet its market. The period of the affiliation contract corresponds to a period during which innovation relies on the platform.

If a plaftorm is the only keystone player in an industry, then the innovation rate depends on it. If there is another keystone player, then the competition rises and innovation has to go up for a platform in order to attract complementors. This will affect the discount factor.

We will thus rebuild the original model in our first step and in a second step, we will extend the original model by adding a new condition that will affect the discount factor and make it more favorable when a firm has access to two platforms instead of only one.

Indeed, in what follows, we are inspired by the dynamics highlighted in Horowitz and Lai (1996) and we apply their model to the relationship between affiliation contract's length and innovation in an industry. We will rely on the same hypothesis, which is that affiliations with a long term lead to a higher innovation rate.

In Horowitz and Lai (1996), the marginal cost of innovation is noted $c$ and is supposed to be constant. There are also potential complementors who may find it financially interesting to replicate some platform characteristics after the affiliation contract period. Thus, if the keystone player develops its innovation in the $t$ period, the complementor will be able to produce it in the $t+\tau$ period. The replication cost is assumed to be zero. The unit cost of production (distinct from the costs of innovation $=\mathrm{RD}$ ) is constant and denoted $\beta$. Furthermore, $t=[-1,0,1,2 \ldots$ [ where $t=-1$ represents a pre-existing technology, and $t=0$ represents the period in which the innovation can occur. The position of the better quality product at the period $t$ is noted as $n_{t}, p$ is the price of the product, and $x$ is the quantity purchased by consumers. The position on the scale of the most advanced product that can be replicated in the $t$ period is denoted $m_{t}$. 
Also, we include this model in the vertical differentiation framework. We assume that innovations will lead to a greater vertical differentiation position compared to the previous level. $\phi$ will represent the position in terms of vertical differentiation. From there, we can define the marginal change following an innovation of one company, denoted $n$, compared to the state of the art in terms of innovation in the market, denoted $m$ : $\phi^{n-m}$. We also assume that $\phi>1$.

\subsubsection{Keystone player's incentive to innovate}

Under these conditions, the keystone player at the $n$ position produces at a price computed according to the following equation:

$$
p_{n}=\beta \times \phi^{n-m}
$$

The lowest price at which the complementor will sell its product at the $m$ position will be $p_{m}=\beta$. By adopting a limit price strategy, the keystone player captures the entire market, and the marginal utility $(\mu)$ per dollar for the good at the $n$ position is higher than for the good at the $m$ position, as represented by the following equation:

$$
\frac{\mu_{n}}{p_{n}}=\frac{\phi^{n}}{\beta \times \phi^{n-m}}=>\frac{\mu_{m}}{p_{m}}=\frac{\phi^{m}}{\beta} .
$$

The net revenue of the keystone player at the $t$ period is therefore computed according to the following equation:

$$
\pi_{t}=\left(p_{n}-\beta\right) \times x_{n}=\left(p_{n}-\frac{p_{n}}{\phi^{n-m}}\right) \times x_{n}=\left(1-\frac{1}{\phi^{n-m}}\right) \times p_{n} \times x_{n} .
$$

The description of the complementor's innovation can be represented by the following equation:

$$
m_{t}=0 \quad 0 \leq t<\tau \quad m_{t}=n_{1-\tau} \quad t \geq \tau
$$

After the affiliation contract expires, the complementor's position is the one the keystone player occupied $\tau$ periods earlier, i.e. $n_{1-\tau}$.

The keystone player will seek to maximize the present value of the net revenue stream represented by the previous equation:

$$
\max _{\langle n(t)\rangle_{\tau=0}^{\infty}} \sum_{t=0}^{\infty} \delta^{t}\left[\pi_{t}\left(n_{t}, m_{t}\right)-C\left[n_{t}-n_{t-1}\right]\right],
$$

where $\delta$ is the discount factor $(0<\delta<1)$.

The first-order conditions with respect to $n_{t}$ are:

$$
\delta^{t} \times \frac{\partial \pi_{t}}{\partial n_{t}}+\delta^{t+\tau} \times \frac{\partial \pi_{t+\tau}}{\partial n_{t}}-\left(C \times \delta^{t}+C \times \delta^{t+\tau}\right)=0 .
$$

Solving the previous equation, we obtain the following result:

$$
\left[\phi^{m_{t}-n_{t}}-\delta^{\tau} \times \phi^{n_{t}-n_{t+\tau}}\right] \times p_{n} \times x_{n} \times \ln \phi=C \times[1-\delta] .
$$

In other words, the marginal revenue from innovation $n_{t}$ is equal to the marginal cost. Hence, we can look now into the innovation incentive for the keystone player represented by the following equation: 


$$
\phi^{n_{t-\tau}-n_{t}}=\frac{C \times(1-\delta)}{\left(1-\delta^{\tau}\right) \times p_{n} \times x_{n} \times \ln \phi} .
$$

We have determined the innovation incentive for the keystone player created by the presence of complementors. It is interesting now to look at the innovation rate in the industry.

\subsubsection{Total innovation in the industry}

The keystone player has an $R \& D$ program that consists of introducing new products or services each time the previous affiliation contract expires. The size of the innovation - hence the size of the R\&D investment - can be measured by:

$$
n_{t}-n_{t-\tau}=\frac{1}{\ln \phi} \times \ln \left[\frac{\left(1-\delta^{\tau}\right) \times p_{n} \times x_{n} \ln \phi}{C \times(1-\delta)}\right] .
$$

Since $0<\delta<1$, the size of the investment increases with the duration of the affiliation contract. Also, a constant-size innovation will be generated every $\tau$ period: $[0, \tau, 2 \tau, 3 \tau, \ldots]$.

An important concept is the notion of innovation frequency. It can be defined as $1 / \tau$.

We can now formally introduce the innovation rate concept. Denoted $\omega_{1}$, the innovation rate can now be defined as follows:

$$
\omega_{1}=\frac{\left(n_{t}-n_{t-\tau}\right)}{\tau} .
$$

By resolving the previous equations, we obtain the following result:

$$
\phi^{-z \times \tau}=\frac{C \times(1-\delta)}{\left(1-\delta^{\tau}\right) \times p_{n} \times x_{n} \times \ln \phi} .
$$

The innovation rate can then be extracted as a function of costs, frequencies and discount factors, which leads to the following equation:

$$
\omega_{1}=\ln \left[\frac{\left(1-\delta^{\tau}\right) \times p_{n} \times x_{n} \times \ln \phi}{C \times(1-\delta)}\right] \times \frac{1}{\tau \times \ln \phi} .
$$

Thus, an increase in the duration of the affiliation contract $\tau$ decreases the frequency of innovation, which negatively influences the innovation rate. However, a larger $\tau$ increases the size of innovation, which positively influences the innovation rate.

There is however a necessary condition for a positive innovation rate, which is represented by the following equation:

$$
\left(1-\delta^{\tau}\right) \times p_{n} \times x_{n} \times \ln \phi>C \times(1-\delta) .
$$

It is possible to determine the maximum innovation rate based on the term of protection of the affiliation contract:

$$
\left.\frac{\partial \omega_{1}}{\partial \tau}=-\frac{1}{\tau^{2} \times \ln \phi} \times \ln \left[\frac{\left(1-\delta^{\tau}\right) \times p_{n} \times x_{n} \times \ln \phi}{C \times(1-\delta)}\right]-\frac{\delta^{\tau} \times \ln \delta}{1-\delta^{\tau}}\right)=0,
$$

which leads to the following equation: ${ }^{8}$

\footnotetext{
${ }^{8}$ See proof in the appendix for further details.
} 


$$
\left(1-\delta^{-\tau}\right) \times \ln \left[\frac{\left(1-\delta^{\tau}\right) \times p_{n} \times x_{n} \times \ln \phi}{C \times(1-\delta)}\right]=\tau \times \ln \delta
$$

We can now determine the optimal rate of innovation with one keystone player in an industry:

$$
\omega_{1}^{*}=\frac{\delta^{\tau *} \times \ln \delta}{\left(1-\delta^{\tau *}\right) \times \ln \phi}
$$

This provides us with a fascinating set of results and, in particular, the optimal point in terms of time and innovation rate. Indeed, it can be represented on the following graph with the optimal innovation level based on the affiliation contract's length with the keystone player $\tau_{1}^{*}, \omega_{1}^{*}$. The curve's convexity is also interesting in terms of legal interpretation. A keystone player's presence is incredibly essential for innovation on the market as such, with a sharp slope when $\tau<\tau_{1}^{*}$. However, it is then clear that biased market power in favour of the keystone player may hinder innovation in this industry, although the small absolute value of the slope highlights the fact that the negative impact on the industry's innovation rate may not seem too obvious. As an aside note, it is also another benefit of the formal theoretical representation of this article.

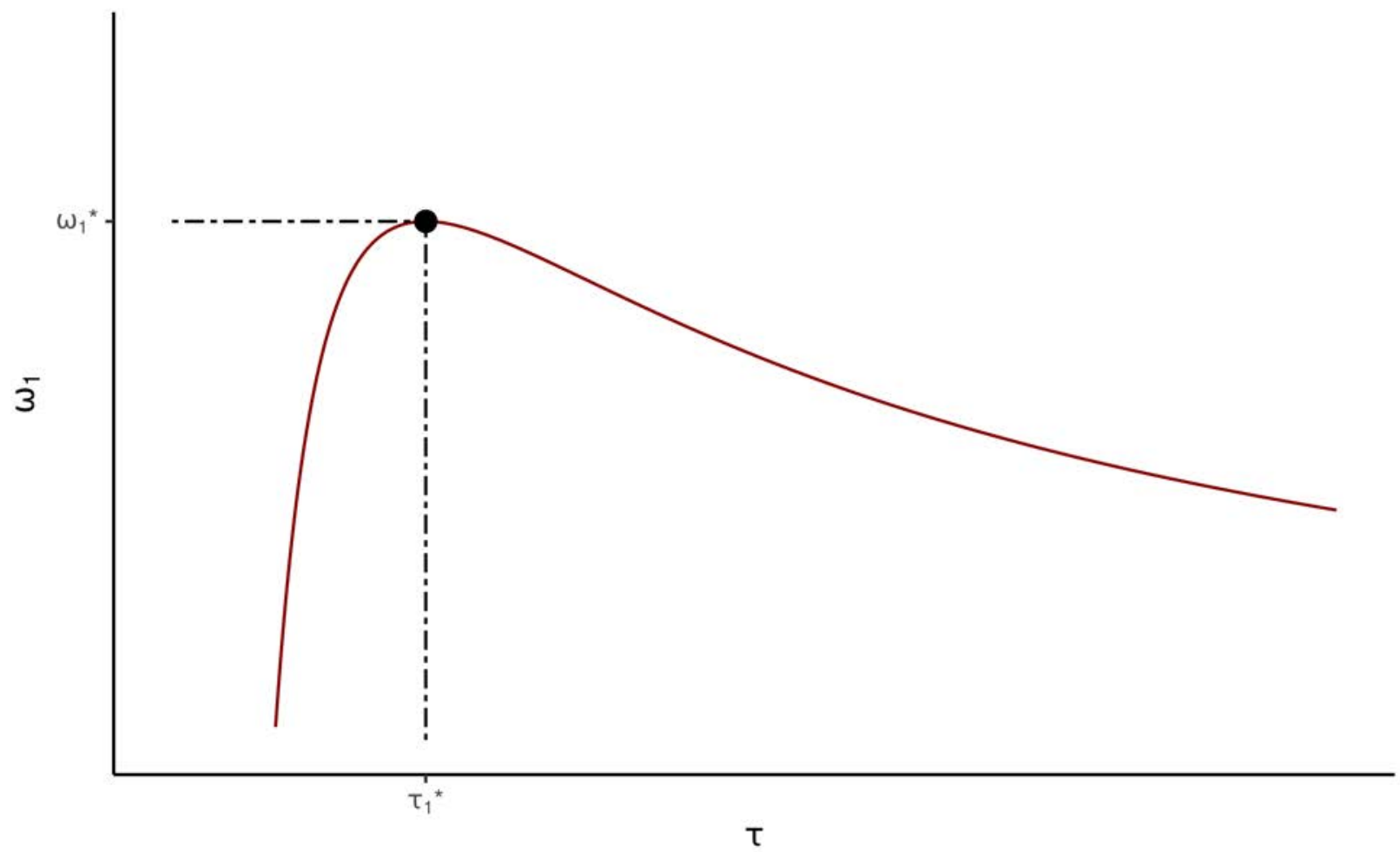

Figure 1. Optimal innovation rate, computed with the following calibration for the parameters: $\delta=.08$, $p_{n}=2, x_{n}=2, \phi=10, C=2$ and $\theta=1.1$.

Let us now move to the Bayesian approach where we introduce a prior, denoted and capturing the possibility of switching to a concurrent digital platform. Two related parameters are thus important to consider: the duration of the affiliation contract and the switching costs.

\subsection{Innovation when there is some competition with other platforms}

Let us now augment the previous base model with a new hypothesis. 
Hypothesis 2: When an industry is composed of more than one keystone player, the optimal innovation is higher.

When we consider the possibility to access other innovation ecosystems (or other digital platforms), the revenue is impacted by the potential access to other platforms with a factor, denoted $\theta$ with $\theta>1$ in this article. is our Bayesian prior

A further contribution could be to relax this condition in order to capture efficient ecosystems to less efficient ecosystems. Hence, $z$ can be re-written $\omega_{2}$, The following equation defines $\omega_{2}$ :

$$
\omega_{2}=\ln \left[\frac{\left(1-\theta \times \delta^{\tau}\right) \times p_{n} \times x_{n} \times \ln \phi}{C \times(1-\delta)}\right] \times \frac{1}{\tau \times \ln \phi} .
$$

It is again possible to determine the new maximum innovation rate based on the terms of the affiliation contract, as calculated in the following equation:

$$
\begin{gathered}
\frac{\partial \omega_{2}}{\partial \tau}=-\frac{1}{\tau^{2} \times \ln \phi} \times \ln \left[\frac{\left(1-\theta \times \delta^{\tau}\right) \times p_{n} \times x_{n} \times \ln \phi}{C \times(1-\delta)}\right]-\frac{\theta \times \delta^{\tau} \times \ln \delta}{1-\delta^{\tau}}=0 . \\
\frac{\left(1-\delta^{-\tau}\right)}{\theta} \times \ln \left[\frac{\left(1-\delta^{\tau}\right) \times p_{n} \times x_{n} \times \ln \phi}{C \times(1-\delta)}\right]=\tau \times \ln \delta .
\end{gathered}
$$

Hence, as a result, we determine the new optimal rate of innovation, when in the presence of a concurrent digital platform, as represented by the following equation:

$$
\omega_{2}^{*}=\frac{\delta^{\tau *} \times \theta \times \ln \delta}{\left(\delta^{\tau *}-1\right) \times \ln \phi}
$$

We have a new maximum $\tau_{2}^{*}, \omega_{2}^{*}$ with, as a result, $\omega_{2}^{*}>\omega_{1}^{*}$ and interestingly enough $\tau_{2}^{*}<\tau_{1}^{*}$. 


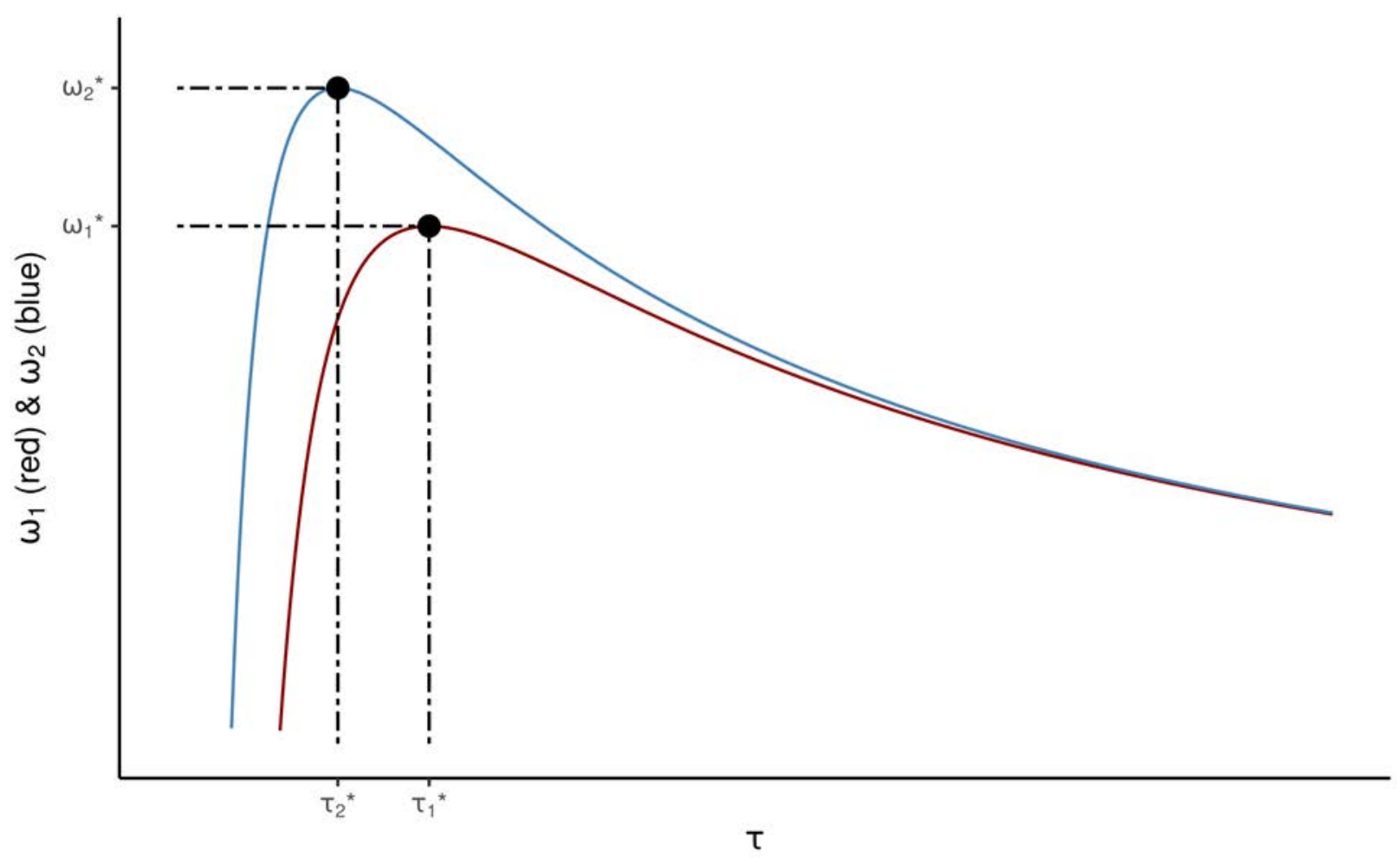

Figure 2. Optimal rates of innovation, computed with the following calibration for the parameters: $\delta=.08$, $p_{n}=2, x_{n}=2, \phi=10, C=2$ and $\theta=1.1$.

As a result, the optimal innovation rate is higher, but it benefits the industry when the affiliation contract's length is shorter. It is also crucial to note that these results are not against the presence of keystone players, but to the contrary, an argument can be made on the positive role of keystone players when looking at the innovation acceleration provided by the general-purpose technology they offer through their platforms.

Based on these results, we think it is easier to grasp the subtleties of the - sometimes - contradictory conversations in the literature. Indeed, as aforementioned we have two scenarios in the literature: one that demonstrates that keystone players are important innovation enhancers, and another one that demonstrates with force evidence that keystone players can be a threat to innovation dynamics.

When considering a conventional methodological paradigm, both scenarios can be true in their own context. This is why Bayesian empirical approaches have to be favoured in this context. Researchers need to define a prior corresponding the issue at stake. With the proposed theoretical framework, in the methodological dimension, we demonstrate how the introduction of a prior can lead to more complex results.

In the competition law domain, we demonstrate that keystone players may indeed have both a positive and a negative impact on innovation dynamics. The presence of a keystone player is a terrific enhancer of innovation in an industry as long as the affiliation contract duration is below the optimal rate of innovation. In our case, the duration can be translated in a lock-in effect within a given ecosystem. The duration is excessive as soon as the switching costs, that increased with the duration of the partnership, tend to be so high as they hinder any capacity to stop to cooperate with the keystone. In other words, a too long relationship may lead to an exclusive contract (single-homing) or to a situation of economic or technological dependence.

Beyond the optimal point, it has a negative impact. However, the first and second derivatives matter here. Before the optimal point, it is easy to find empirical evidence of the benefits in terms of innovation of 
the presence of keystone players. After the innovation point, the slope and its convexity demonstrate the more nuanced and subtle interpretations. Indeed, the innovation rate is still high and close to the optimal point. Researchers need a dynamic and a more long-term perspective to be able to capture the negative first derivative. A static perspective may not lead to the negative interpretation.

Those lessons are extremely important for competition law enforcement. It is important to have a sound framework capturing the dynamics in an industry and being able to have a more complex perspective than just a binary perspective. Of course, in this article, we made the deliberate choice to look at innovation. In itself, it is a philosophical bias towards a dynamic perspective of competition versus a more static analysis based on market structures.

\section{Lessons for Competition Law}

\subsection{Benefits of a keystone player-based ecosystem}

As demonstrated in the formal model, keystone players are successful for they have built an effective technological infrastructure. Complementors can indeed benefit from multiple dimensions:

- First, there is the dimension related to the technological nature of the platform: (1) scale economies and network economies, (a)2) ccess to resources potentially reducing barriers to entry, (3) dedicated application programming interfaces (API), (4) AI-based recommender systems, and (5) general cloudbased services.

- Second, comes the dimension related to the business nature of the platform: (1) financial incentives (gains sharing related to the collection and processing of data by the keystone), (2) a potential protection against competition at least in the short-term (from competing "complementors" - if exclusive partnership or "elite" partnerships - or even from the keystone itself - implicit commitment not to compete with its complementors), (3) pooling of risks and investments, (4) possible monitoring of the other members of the ecosystem (nowcasting and possibility of "advanced" neutralization in case of development of a "disruptive" technology for the ecosystem), and (5) Incentives to single-homing for complementers through mechanisms leading to exclusivity (also a logic of pre-emption to the detriment of competing ecosystems).

In short, ecosystem integration has favorable effects - it increases the overall rate of innovation in that it lowers barriers to entry to innovation (reducing costs and risks) and it allows the coordination of investments between different ecosystem members. As such, it resolves the radical uncertainty about the investment decisions of others. It may also provide some exclusivity. It may offer a form of inter-operability as well as easy access to consumers (e.g. via the application store).

Paradoxically, an ecosystem escapes market forces and enters into an hybrid form or even an integrated organizational form à la Coase (1937). There is less uncertainty and potentially no unnecessary duplication of investments in a sector where fixed costs are high and replication costs are very low.

Several issues could also be addressed. Some are related to applying the model to the digital world and others to the consequences in terms of competition policies.

\subsection{Innovations and digital ecosystems: what specificities?}

The first set of questions relates to the validity of extending a platform-to-business affiliation contract model to digital ecosystems. One difference could lie in the limitation of exit possibilities. These are possibly more significant because of the hub's competitive pre-emption capacity and the possibilities of strategic reduction of inter-operability. Indeed, the case of digital enterprises and their ecosystems presents specificities concerning inter-company cooperation models.

It should indeed be noted that compared to traditional activities, digital technology has a favourable impact on the various dimensions that affect collective innovation behaviour. These dimensions are: the question of complementarities, coordination costs, but also dimensions related to the replicability of technologies, their 
appropriability or the ability of the various stakeholders to detect opportunities. As noted by Bauer and Prado (2020), "[The digital economy] is more plastic than mechanical technology, allowing a larger set of technological combinations to produce output, and accelerates the speed of change by reducing the cost of innovation." Digital ecosystems also make it much more comfortable than in traditional configurations to coordinate investments between independent players. Coordination facilitation can be achieved through contracts giving access to critical resources in terms of data, application programming interfaces, interoperability protocols, etc.

In what follows, we will see that these very measures can create situations of dependence and vulnerability for complementors and allow the keystone to neutralize potential competitive threats (Marty, Harnay, and Toledano 2019). In other words, radical innovations from complementors could hinder incremental innovations in which the keystone is the primary beneficiary. The keystone position allows the innovation dynamics to be skewed in favour of the keystone, which may be unfavourable to the complementors and consumers. This bias can result, as we have seen, in predatory or at least consolidating innovations.

The innovation dynamics can also present another risk: complementors may only develop innovations at the module level and not at the architecture level (Yoo 2016). Only the keystone player can do this. However, its decisions - potentially unilateral - can significantly degrade ex-post the profitability of the complementors' investments, while at the same time proving to be favourable to the innovation dynamics as a whole or to the consumer. The keystone's ability to act unilaterally is all the more problematic because it can play favourably or unfavourably concerning its complementors (De Meyer and Williamson 2020). Some of its decisions may favour them as soon as their interests are aligned, but the structuring power exercised may allow them to expropriate their potential rents or even exclude them from the market. This credible threat can bias the complementors' decisions by encouraging them to engage in innovation dynamics that consolidate the keystone's position.

\subsection{Identification of competitive risks}

The second set of questions relates to the field of competition economics. We consider now the risks of competitive harm. The latter may be due to the development of anti-competitive exclusionary strategies (such as kill zones), to the possible exercise of regulatory power within ecosystems, to advantages linked to asymmetric access to data, and finally to possible abuses of economic or technological dependence.

\subsubsection{Ecosystems, innovations and kill zones}

First of all, several questions can be considered concerning the literature on kill zones.

The damage to third parties and innovation is, in the case we describe, more complex than the current literature, which is essentially based on the case of biotechs (in which the notion of killer acquisitions was crafted). Damage can occur through indirect effects, as shown by Caffarra, Crawford, and Valletti (2020). Indeed, once the target is acquired, it is the acquirer's R\&D that may disappear. Second, innovation driven by current ecosystems may not make possible a scenario often defended in antitrust: laissez-faire based on the self-regulation of digital markets. In this approach, doing nothing is a good option due to their technological turbulence of these markets. The innovation game would be enough to resolve the risk of a long-term concentration of market power as it did with Rank Xerox, IBM or Microsoft. Here, the effects of an ecosystem lock-in (both technical complementarities and contractual clauses) reduce this scenario's likelihood.

Moreover, the algorithmic and computational capabilities of the keystone players make the risk of profitable exits, as shown in the model, and the risk of unanticipated disruption much less likely. The problem is one of investment coordination in the first place (adjustments take time and require access to technical interface protocols), and in the second place, it is one of controlling critical resources. These resources are related to data, but not only to data. Critical assets cover programming interfaces, computational capacities, and physical assets (connected objects, infrastructures, etc.).

The keystone has private regulatory power over its ecosystem: it decides on prices and market access for its complementors, but also may influence their investments and technological development. The more long- 
term and structural the integration in the ecosystem is - e.g. the longer the duration of the partnership the more the complementor will depend on the keystone's technologies and market access (it depends on its APIs and only accesses the market through it. Another example is about the payments that the keystone provides. which may act as exclusivity clauses. Indeed, not opting for single-homing contract may result in losing the "loyalty bonuses."

\subsubsection{Ecosystems and technological externalities}

The capacity to control the environment is much more substantial for today's ecosystems than for the dominant operators of previous decades.

Firstly, controlling massive data and continuously renewed and diversified data can significantly enhance algorithm performance. This performance can result in better service (finer predictions and recommendations) and enhanced competitive threat detection capabilities. Not only is it becoming less and less sure that competition on the merits is possible (i.e. that competitors can be more "efficient" in terms of quality of service rendered), but also that the keystone player may not detect a possible competitive threat sufficiently in advance. The question of mergers and acquisitions that we have discussed above can be reconsidered from this perspective. The keystone may engage in consolidating acquisitions to pre-empt the most massive flows of data that reinforce both the performance of the services provided by its ecosystem and the "essential nature" of access to it for its complementors.

The keystone can also acquire firms whose activities are likely to prove strategic concerning its ecosystem and potential competition with other ecosystems. However, such acquisition does not necessarily have to be conceived as a killer acquisition but as a consolidating acquisition that may prove favourable to the shareholders of the acquired firm and to a certain extent to the consumers who will benefit from a better integrated, less costly and undoubtedly more efficient service - due to the pooling of technical capacities and the support of financial capacities that are not on a par with those that an independent player could benefit from. Merger control is incredibly difficult to implement in the context of such acquisitions (Committee 2020). This ability to protect market structures - and the innovation dynamics - ex-ante through merger control is all the more questionable since transactions can occur even before the acquired company has entered the market (Drexl 2012).

As Ezrachi and Stucke (2020, p. 39) note, the former dominant operators (even Microsoft in the early 2000s) could not know in real-time what their competitors were doing and especially not what they were planning to do. The ability to implement nowcasting strategies (predicting the present) based on constant monitoring of online content allows them to discern very early on any trends that could create threats or opportunities. ${ }^{9}$ This ability to deal with potential threats stems from the financial and technical capacity to buy out companies that could be nascent competitors, to clone their services or reduce their access to the market, by manipulating the algorithms that could present them to consumers, by setting up frictions on their use or by degrading their quality through a strategic game on inter-operability protocols. ${ }^{10}$ In the end, two potential costs linked to this situation should be considered: one in terms of the loss of incentives specific to a neck-and-neck competition to develop innovations between the keystone and the firm concerned, and the other one in terms of locking up the ecosystem.

Second, in addition to these advantages in terms of quality and control of competitive threats, the keystone player's infrastructure may create barriers to entry through the share of consumers and complementors who are only accessible through it, insofar as they have opted for single-homing. This infrastructure can also play a decisive role in creating a situation of economic and technical dependence or the appearance of risks of asymmetrical access to data (which is fundamental to the algorithm's performance). That can compromise

\footnotetext{
9 "Nowcasting also represents a potent data-based weapon: the ability to monitor new business models in real time. The dominant platform can use its relative advantage in accessing and processing personal data, such as watching for trends in its proprietary data from posts on a social network, search queries, emails, and the like, to quickly identify (and squelch) nascent competitive threats. The dominant firm can acquire entrants before they become significant competitive threats. Or it can blunt the entrants' growth, by copying the innovation or promoting its own version"

10 "The dominant firm can make it harder for consumers to see the innovator's product (such as manipulating its search engine results to make it harder to find the original innovation or removing the innovation from its platform's app store), or degrading the rival product's functionality" (Ezarchi et Stucke, 2020, p.40)
} 
the level playing field by reducing the uncertainty that the keystone has to face, as opposed to a situation in which its complementors can make their own decisions.

Google, Amazon and Microsoft, for instance, hold strategic positions in terms of cloud information, whether it is the provision of storage capacity, computational capacity, data sets available to train AI or algorithmic capabilities. These services rely on highly specific and capital-intensive assets, infrastructures and capabilities. As their amortization is incredibly difficult, if not impossible, for most firms, such capacities play as barriers to entry.

In doing so, both complementors and direct competitors or even dominant operators in other digital markets (Netflix, Airbnb, Spotify, TikTok, Snap ${ }^{11}$ ) must use the capacities offered for rent by these large firms. ${ }^{12}$ Beyond cost arguments, the choice to use these infrastructures is based on scalability issues (both up and down) but also on performance. It is also an activity where the performance will depend on economies of scale and scope. Moreover, the same performance of the algorithmic services rendered depends on real-time access to massive and diversified data.

\subsubsection{Ecosystems and benefits in terms of data collection and processing capacity}

The development of AI algorithms is not only "data intensive" but also computationally intensive. As noted by the CNMC and the Autoritat Catalana de la Competència, in their Artificial Intelligence and Competition note ${ }^{13}$ the development of competitively efficient algorithms requires access to specific and expensive assets:

"Additionally, some AI algorithms mainly those involved in deep learning are computationally intensive. To train a neural network, which can have a trillion neurons trained in thousands of training iterations, high processing capacity is required. In order to achieve some efficiency, specialized AI processors are used to reduce training times."

However, a minimal number of actors can invest in these infrastructures. ${ }^{14}$ Once the investment has been made, they are essential for third parties to have the capacity to control vast pools of data, storage capacity and algorithmic processing required for the development. Not having this capacity is a barrier to entry. Having it available through a limited number of operators ${ }^{15}$ (AWS, MS Azure, Google Cloud Platform, IBM Cloud...) can create technical dependence and could lead to fears of possible abuses that are difficult to characterize in competitive terms. Asymmetrical access to these capabilities (in terms of quality or cost) could significantly affect algorithm performance. The absence of guarantees of neutrality and confidentiality could hinder downstream competition and the competitive dynamics related to possible quality and specificity differentials in developing solutions provided by the various firms. To the extent that competition cannot be based on price but only on quality, limited access to essential development capabilities may hinder the competitive process by allowing a few players to control their customers' technological dynamics, who are also their complementors and competitors in current and future related markets.

Beyond data, storage capacities, computational capacities, and algorithmic capacities could be regulated as essential facilities in the very sense that European competitive jurisprudence has given to this term.

Indeed, for the CNMC and the ACCO:

"While processing capacity is essential to the implementation of AI, to guarantee the existence of $\mathrm{AI}$, it is also essential to ensure that undertakings can access such processing capability (in

\footnotetext{
${ }^{11}$ Snap Inc., annual report (Form 10-K), February 4, 2020.

${ }^{12}$ Three access models can be analyzed. The first is IaaS (infrastructure as a service). Customers access data centers and servers supplied by a service provider. The second level is the PaaS (platform as a service). It is then possible to access operating systems and tools for database management and software development. The third and final level is SaaS (software as a service). The applications made available to customers are then directly accessible on the cloud.

${ }^{13}$ Published in September 2020 in response to the public consultation launched by the European Commission following the publication on February 19, 2020, of its white paper on Artificial Intelligence

${ }^{14}$ The U.S. Congress Judiciary Committee (2020, p. 116) compares the cost of deploying large companies' cloud computing infrastructure to the equivalent of a cellular phone network. Not only are the costs of renting services falling, but the very marketing of services is based on incredibly demanding aspects in terms of certifications and reputation, which further limits the likelihood of internalization by customers or new entries into the industry.

${ }^{15}$ Amazon has been active in this market since March 2006, Microsoft since October 2008 and Google since June 2012.
} 
both software and hardware, and cloud computing) in a neutral manner. The need to analyze this processing market is even greater insofar as it is highly concentrated among few suppliers that could have a clear conflict interest as companies providing AI tools while also being users of the same tools".

The keystone player's position means that the dominant firm is at the same time a lock on its ecosystem, its regulator and a competitor with a decisive informational advantage over the other participants. Dominance over the ecosystem, which is reinforced by vertical integration - especially upstream - can make competition in the market (i.e. in the ecosystem) impossible. These structural failures may harm the innovation dynamics.

Snapchat's annual financial report (10K-Form) highlights the essential nature of these resources but also the risks that can arise:

"We rely on Google Cloud and Amazon Web Services, or AWS, for the vast majority of our computing, storage, bandwidth, and other services. Any disruption of or interference with our use of either platform would negatively affect our operations and seriously harm our business. Google and Amazon provide distributed computing infrastructure platforms for business operations, or what is commonly referred to as a"cloud" computing service. We currently run the vast majority of our computing on Google Cloud and AWS, and our systems are not fully redundant on the two platforms. Any transition of the cloud services currently provided by either Google Cloud or AWS to the other platform or to another cloud provider would be difficult to implement and will cause us to incur significant time and expense. We have committed to spend $\$ 2.0$ billion with Google Cloud over five years and $\$ 1.1$ billion with AWS over six years, in each case beginning January 2017, and have built our software and computer systems to use computing, storage capabilities, bandwidth, and other services provided by Google and AWS. Given this, any significant disruption of or interference with our use of Google Cloud or AWS would negatively impact our operations and our business would be seriously harmed."16

\subsubsection{Ecosystems and abuse of economic and technological dependency}

Beyond the technological risks (inducing a possible abuse of technical dependence), two additional risks must be considered: the first is a possible abuse of economic dependence, and the second is a strategic use of asymmetrical access to information.

Once again, the February 2020 financial report of Snap Inc. s February 2020 financial report shows how competitors from large ecosystems that need to use their tools can fall victim to abusive strategies that echo the European Commission's issues in its June 2019 platform to business regulation. Snap Inc.'s annual report allows us to characterize these risks:

"Besides, each of Google and Amazon may take actions beyond our control that could seriously harm our business, including:

- discontinuing or limiting our access to its cloud platform;

- increasing pricing terms;

- terminating or seeking to terminate our contractual relationship altogether;

- establishing more favourable relationships or pricing terms with one or more of our competitors; and

- modifying or interpreting its terms of service or other policies in a manner that impacts our ability to run our business and operations.

Google and Amazon each have broad discretion to change and interpret its terms of service and other policies with respect to us, and those actions may be unfavorable to us. They may also alter how we are able to process data on their cloud platforms. If Google or Amazon makes changes or interpretations that are unfavorable to us, our business could be seriously harmed". ${ }^{17}$

\footnotetext{
${ }^{16}$ Snap Inc. financial report, page 11.

${ }^{17}$ Financial Report Snap Inc. Page 11.
} 
After the risks linked to unbalanced bargaining power (increased access costs, worsening access conditions, etc.), the risks linked to asymmetrical access to data between the service provider and its client should be noted. The latter may only have imperfect access to its data when the former has an overhanging view of all the data generated by all the participants in its ecosystem. This issue is central to the investigation opened in July 2019 by the European Commission against Amazon. It can be extended to using the data collected and observed from partners to improve the performance of its service. ${ }^{18}$

This second risk is highlighted by the U.S. Judiciary Committee in its October 2020 report (Committee 2020, 361). Taking the case of Apple's mobile ecosystem, the report notes that Apple, through data collected and observed via iOS and the App Store, is implementing a Sherlocking strategy. This strategy is based on the fact that the keystone player can "collect competitively sensitive information about popular apps and then build competing apps, or integrate the popular app's functionality into iOS."

This service replication capacity is coupled with an algorithmic information processing capacity enabling the detection of weak market inflection signals and controlling the environment and competitive dynamics. The fear is based on the fact that, following the example of Apple, presented above, the various operators can "closely track usage trends and growth patterns of third-party apps" with an almost perfect understanding of the market based on the use of AI, over which these operators have a decisive advantage.

The investments made by leading firms in these forecasting capabilities for the immediate future are based on their internal and external growth. One example is Google's acquisition of Looker (in February 2020). Looker is a start-up specialized in data analysis applied to start-ups development (Committee 2020, 387). For some observers, cited in the House of Representatives report, such acquisitions can have a double anticompetitive effect. On the one hand, they eliminate a potential competitor in a strategic activity (and internalize its capabilities), and then they deprive competitors and other independent players of access to its services, which mechanically reinforces the essential nature of the keystone player.

\section{Policy recommendations and conclusion}

This last section outlines some avenues for regulatory tools or the implementation of competition rules to limit the competitive risks described above that could damage innovation.

The U.S. Judiciary Committee report (Committee 2020, 377) proposes to resolve these conflicts of interest through the structural separation of the different business lines. ${ }^{19}$ In that case, regulation of these services along the network industries' lines could be a hypothesis to consider (Khan 2019). It could take the form, on the one hand, of a right of access under reasonable, fair, non-discriminatory and cost-oriented conditions and, on the other hand, of guarantees regarding access and data processing (in a logic of erecting a Chinese Wall between the different lines of business).

If we consider the first aspect, the usual activation criteria of the theory of essential facilities seem to be met: an infrastructure that is impossible to replicate under reasonable conditions in technical and financial terms, owned by a dominant player, whose access - unbiased - is essential for efficient market access and for which a possible refusal of access is not justified. Access on reasonable, fair and non-discriminatory terms (comparable to the logic of a FRAND license) would be necessary. Access under these conditions should not alter the incentives to invest of the operators, and a refusal of access would prevent, if not new products, at least subsequent innovations within the meaning of the European Commission's Microsoft decision of March 2004 .

However, the firm at the heart of the ecosystem can, by making these capacities available, whether through rental contracts or an obligation of access, prevent investments by its competitors or even strategically access their data flows to improve its prediction tools and thus reinforce the risk of kill zones described above.

Similarly, these tools can lead complementors into a situation of competitive lock-in that can turn into a situation of economic and technological dependence. Indeed, changing providers induce high switching costs

\footnotetext{
18 "The surveillance data they collect through their intermediary role, meanwhile, lets them exploit that conflict [of interest] with unrivalled precision" (U.S. Congress Judiciary Committee (2020, p. 378).

${ }^{19}$ Transposing some of the recommendations of Khan (2019) in The separation of platforms and commerce.
} 
and raises many technical issues. ${ }^{20}$

However, two questions remain. The first is that of the very qualification of dominance within the meaning of the rules of competition. The different ecosystems compete with each other, and none is individually dominant. However, some firms are dependent on an ecosystem (relative dominance and competitive lockin), and these platforms form a model of oligopoly in potentially increasingly tight silos. The second is that of a competition authority's capacity to oversee these issues of access and the respect of guarantees of equal access and confidentiality in treatment. In both cases, recourse to ad hoc regulatory authorities may appear to be a useful tool for ex-ante supervision and prevention of ex-post damage for which competition rules offer only imperfect restorative remedies.

For instance, following the example of those announced by the European Commission in June 2020 or envisaged by the US House of Representatives' report in October 2020, this is the case for data portability, inter-operability guarantees and neutrality requirements, which are included in most projects. The case of data portability deserves the end of this discussion. Ezrachi and Stucke (2020, p. 74) insist on the fact that access to the "stock" of personal data may be insufficient to allow balanced competition within and between ecosystems. Building on Scott Morton et al. (2019), Gal and Petit (2021) emphasize that in digital ecosystems, competition can only occur for the market but only marginally in the market. In other words, competition occurs more between different silos than between members of the same ecosystem. This may support our hypothesis of an innovation dynamics characterized by a plateau rather than a decline to generate and exploit data to cope with potential intra-ecosystem competition (which can be controlled) and inter-ecosystem competition (which can be partially controlled through lock-in strategies and acquisitions of start-ups). Intra-ecosystem competition tends to distort the composition of innovation, favouring incremental (or even lock-in) innovations. The persistence of (potential) competition between ecosystems may explain the persistence of (probably protective) investments in breakthrough innovations. Not only is non-personal data necessary, but a level playing field requires access to a complete set of up-to-date and diverse data. For example, nowcasting strategies require instant access to data streams. Gal and Petit (2021) also conclude on the limits of the data-sharing instrument and proposes - in case the data has been acquired, observed or inferred through anti-competitive practices - to allow competitors to access not the data but the algorithms developed from it.

The doubts displayed by Gal and Petit (2021) about traditional competitive remedies (such as access to data) are therefore based on the fact that they do not allow for the re-establishment of a level playing field about the advantages, notably informational and algorithmic, of the dominant operators (hence the proposal for mandatory sharing of algorithms trained on richer databases resulting from anti-competitive practices). The quality of the data (in terms of volume, velocity, variety and veracity) allows algorithms capable of machine learning to improve their hypotheses and rules based on the confrontation of their initial predictions with the observed data. In other words, the more data is available, the higher is the algorithm's ability to derive value from the data exploitation. The more massive, diversified and renewed data flows, the faster and more efficiently the predictions are adapted to the environment's changes. Thus, the training of an algorithm on a rich database can generate a positive externality in other databases' processing capacity or learn on them.

The advantages of third-party access to the algorithms for Gal and Petit (2021) are of several orders: (1) low replication costs, (2) immediate effect (more than data sharing, for example) and (3) neutralization of a benefit related to a past anti-competitive practice or no need for supervision.

However, several limitations should be highlighted. As with all remedies based on access to critical infrastructure, the first relates to the adverse effects on the incentives to invest in both the dominant operator and its competitors (Marty and Pillot 2012). The second lies in the difficulty of interpreting the predictions of algorithms that may function as black boxes. The third lies in the potential effects of these shares on the competitive process and the consumer. On the one hand, the pooling of algorithms can foster the emergence

\footnotetext{
${ }^{20}$ The report of the U.S. Congress Judiciary Committee (2020, p. 118) shows that free trial offers function in this type of service as a locking tool: "When a customer's free trial expires it is faced with switching to another provider or starting to pay for the service. Switching requires an investment in terms of time and resources to adpat to the new provider, as well as possibly paying egress fees to the prior vendor. As a result, customers may decline to switch at the conclusion of free trials". In other words, the initial free trial may act as a locking tool and thus be part of a logic of predation based on inter-temporal arbitration by the dominant firm. In doing so, locking is done by both technical (standard) and cost factors.
} 
of tacit collusive equilibria (Gal and Petit 2021, 20). On the other hand, the duplication of "exploitative" algorithms from one competitor to another may further degrade consumer welfare, whether in terms of discriminatory pricing, algorithmic manipulation or invasion of privacy (Gal and Petit 2020, p. 21).

In terms of policy recommendations, we can distinguish two situations: when complementors have only one option in terms of platform and when they have access to multiple platforms. In the former situation, public policies should focus towards preventing harmful competition between ecosystems (looking into the potential effects of exclusivity clauses, and anti-fragmentation clauses). In the latter situation, public policies should look into data portability, inter-operability, and the control of offensive and defensive acquisitions.

The idea is to preserve the contestability of market positions. Indeed, since preserving market competition may be challenging when yields are increasing and when there is a desire to avoid regulating contractual relations within the ecosystem, it is better to preserve the market competition conditions.

On the methodological side, further research should empirically investigate whether innovation dynamics with a keystone player are higher than a market structure close to a pure and perfect competitive market. Our intuition would accept this question as a statement, but again the answer may be more complex than our intuition leads us to think. In any case, it would be interesting to demonstrate this hierarchy with a competitive keystone-based market structure at the top, then a monopolistic keystone-based market structure, and then a no-keystone-based pure and perfect competition market structure. From an empirical perspective, it would be interesting to look into the use of big data to go this route (Warin and Troadec 2016; Warin and Leiter 2012).

Hopefully, our results will inform the conversations on competition law about digital platforms, and may help with the talking points about inter-operability on markets, data portability and the conditions to have multiple digital platforms within the same industry. 


\section{References}

Aghion, Philippe, Nick Bloom, Richard Blundell, Rachel Griffith, and Peter Howitt. 2005. "Competition and Innovation: An Inverted-U Relationship." The Quarterly Journal of Economics 120 (2): 701-28. https: //doi.org/10.1093/qje/120.2.701.

Bauer, Johannes M., and Tiago S. Prado. 2020. "Lessons from Innovation Economics for Digital Platform Policy." ITS Conference, Online Event 2020. International Telecommunications Society (ITS).

Bougette, Patrice, Oliver Budzinski, and Frédéric Marty. 2019. "Exploitative Abuse and Abuse of Economic Dependence: What Can We Learn From an Industrial Organization Approach?" Revue d'economie Politique Vol. 129 (2): 261-86.

Caffarra, Cristina, Gregory Crawford, and Tommaso Valletti. 2020. "'How Tech Rolls': Potential Competition and 'Reverse' Killer Acquisitions."

Coase, R. H. 1937. "The Nature of the Firm." Economica 4 (16): 386-405. https://doi.org/10.1111/j.14680335.1937.tb00002.x.

Committee, Judiciary. 2020. "Investigation of Competition in Digital Markets." U.S. House of Reprentatives.

De Meyer, Arnoud Cyriel Leo, and Peter J. Williamson. 2020. "Ecosystem Edge: Sustaining Competitiveness in the Face of Disruption." Research Collection Lee Kong Chian School of Business, April, 1-224.

Drexl, Josef. 2012. "Anticompetitive Stumbling Stones on the Way to a Cleaner World: Protecting Competition in Innovation Without a Market." Journal of Competition Law 83 Economics 8 (3): 507-42. https://doi.org/10.1093/joclec/nhs019.

Ezrachi, Ariel, and M. E. Stucke. 2020. Digitalisation and Its Impact on Innovation. Vols. Working Paper 2020/07, October. R\&I Paper Series.

Gaffard, Jean-Luc, and Michel Quéré. 2007. "What's the Aim for Competition Policy: Optimizing Market Structure or Encouraging Innovative Behaviors?" In Innovation, Industrial Dynamics and Structural Transformation, 393-405. Springer.

Gal, Michal, and Nicolas Petit. 2021. "Radical Restorative Remedies for Digital Markets." Berkeley Technology Law Journal 37 (1).

Gutiérrez, Germán, and Thomas Philippon. 2018. "How EU Markets Became More Competitive Than US Markets: A Study of Institutional Drift." National Bureau of Economic Research.

Hemphill, C. Scott, and Tim Wu. 2020. "Nascent Competitors." University of Pennsylvania Law Review, Forthcoming.

Hicks, John R. 1935. "Annual Survey of Economic Theory: The Theory of Monopoly." Econometrica: Journal of the Econometric Society, 1-20.

Horowitz, Andrew W., and Edwin L.-C. Lai. 1996. "Patent Length and the Rate of Innovation." International Economic Review 37 (4): 785-801. https://doi.org/10.2307/2527311.

Kamepalli, Sai Krishna, Raghuram Rajan, and Luigi Zingales. 2020. "Kill Zone." NBER Working Paper, no. 27146 (May).

Khan, Lina M. 2019. "The Separation of Platforms and Commerce." Columbia Law Review 119 (4): 9731098.

Lan, Sai, Kun Liu, and Yidi Dong. 2019. "Dancing with Wolves: How Value Creation and Value Capture Dynamics Affect Complementor Participation in Industry Platforms." Industry and Innovation 26 (8): 94363.

Marty, Frédéric, Sophie Harnay, and Joëlle Toledano. 2019. "Algorithmes et décision concurrentielle : risques et opportunités." Revue d'économie Industrielle, no. 166 (June): 91-118. https://doi.org/10.4000/rei.8237. 
Marty, Frédéric, and Julien Pillot. 2012. "Intellectual Property Rights, Interoperability and Compulsory Licensing: Merits and Limits of the European Approach." Journal of Innovation Economics Management, no. 1: $35-61$.

Marty, Frédéric, and Thierry Warin. 2020. "Concurrence et Innovation Dans Les écosystèmes Numériques à L'ère de L'intelligence Artificielle." Concurrences Review, nos. N 1-2020 (February): 36-41.

McIntyre, David P., Arati Srinivasan, and Asda Chintakananda. 2020. "The Persistence of Platforms: The Role of Network, Platform, and Complementor Attributes." Long Range Planning, March, 101987. https://doi.org/10.1016/j.lrp.2020.101987.

Paul, Sanjukta. 2020. "Antitrust as Allocator of Coordination Rights." UCLA Law Review 67 (2).

Petit, Nicolas. 2020. Big Tech and the Digital Economy: The Moligopoly Scenario. Oxford University Press.

Schrepel, Thibault. 2018. "Predatory Innovation: The Definite Need for Legal Recognition." SMU Sci. \& Tech. L. Rev. 21: 19.

Scott Morton, Fiona, Pascal Bouvier, Ariel Ezrachi, Bruno Jullien, Roberta Katz, Gene Kimmelman, A. Douglas Melamed, and Jamie Morgenstern. 2019. "Committee for the Study of Digital Platforms: Market Structure and Antitrust Subcommittee Report." Chicago: Stigler Center for the Study of the Economy and the State, University of Chicago Booth School of Business.

Warin, Thierry, and Daniel Leiter. 2012. "Homogenous Goods Markets: An Empirical Study of Price Dispersion on the Internet." International Journal of Economics and Business Research 4 (5): 514-29. https://doi.org/10.1504/IJEBR.2012.048776.

Warin, Thierry, and Antoine Troadec. 2016. "Price Strategies in a Big Data World." Chapter. Encyclopedia of E-Commerce Development, Implementation, and Management. IGI Global. https://doi.org/10.4018/9781-4666-9787-4.ch046.

Wen, Wen, and Feng Zhu. 2019. "Threat of Platform-Owner Entry and Complementor Responses: Evidence from the Mobile App Market." Strategic Management Journal 40 (9): 1336-67.

Williamson, Oliver E. 1985. "Reflections on the New Institutional Economics." Zeitschrift Für Die Gesamte Staatswissenschaft/Journal of Institutional and Theoretical Economics, no. H. 1: 187-95.

Williamson, Peter James, and Arnoud De Meyer. 2012. "Ecosystem Advantage: How to Successfully Harness the Power of Partners." California Management Review 55 (1): 24-46.

Yoo, Christopher S. 2016. "Modularity Theory and Internet Regulation." U. Ill. L. Rev., 1.

Zhu, Feng, and Qihong Liu. 2018. "Competing with Complementors: An Empirical Look at Amazon. Com." Strategic Management Journal 39 (10): 2618-42. 


\section{Appendix - Proof}

Let us present, here, the details of the optimization process:

$$
\omega_{1}=\ln \left[\frac{p_{n} \times x_{n} \times \ln \phi}{C \times(1-\delta)}-\frac{p_{n} \times x_{n} \times \ln \phi}{C \times(1-\delta)} \times \delta^{\tau}\right] \times \frac{1}{\tau \times \ln \phi} .
$$

Let us define $u(\tau)$, as follows:

$$
u(\tau)=\ln \left[\frac{p_{n} \times x_{n} \times \ln \phi}{C \times(1-\delta)}-\frac{p_{n} \times x_{n} \times \ln \phi}{C \times(1-\delta)} \times \delta^{\tau}\right] .
$$

Now, let us take the first derivative:

$$
\frac{\partial u}{\partial \tau}=\frac{-p_{n} \times x_{n} \times \ln \phi \times \delta^{\tau} \times \ln \delta /(C \times(1-\delta))}{\left(1-\delta^{\tau}\right) \times p_{n} \times x_{n} \times \ln \phi} /(C \times(1-\delta)),
$$

and simplify here:

$$
\frac{\partial u}{\partial \tau}=-\frac{\delta^{\tau} \times \ln \delta}{\left(1-\delta^{\tau}\right)}
$$

Let us look at the optimal innovation rate now:

$$
\begin{gathered}
\frac{\partial \omega_{2}}{\partial t}=-\frac{\delta^{\tau} \times \ln \delta}{\left(1-\delta^{\tau}\right)} \times \frac{1}{\tau \times \ln \phi}-\ln \left[\frac{\left(1-\delta^{\tau}\right) \times p_{n} \times x_{n} \times \ln \phi}{C \times(1-\delta)}\right] \times \frac{1}{\tau^{2} \times \ln \phi}=0 \\
\ln \left[\frac{\left(1-\delta^{\tau}\right) \times p_{n} \times x_{n} \times \ln \phi}{C \times(1-\delta)}\right] \times \frac{1}{\tau^{2} \times \ln \phi}=-\frac{\delta^{\tau} \times \ln \delta}{\left(1-\delta^{\tau}\right)} \times \frac{1}{\tau \times \ln \phi},
\end{gathered}
$$

which leads to:

$$
\ln \left[\frac{\left(1-\delta^{\tau}\right) \times p_{n} \times x_{n} \times \ln \phi}{C \times(1-\delta)}\right] \times \frac{\left(1-\delta^{\tau}\right)}{\delta^{\tau}}=-\tau \times \ln \delta
$$

then:

$$
\ln \left[\frac{\left(1-\delta^{\tau}\right) \times p_{n} \times x_{n} \times \ln \phi}{C \times(1-\delta)}\right] \times\left(\delta^{-\tau}-1\right)=-\tau \times \ln \delta,
$$

and:

$$
\ln \left[\frac{\left(1-\delta^{\tau}\right) \times p_{n} \times x_{n} \times \ln \phi}{C \times(1-\delta)}\right] \times\left(1-\delta^{-\tau}\right)=\tau \times \ln \delta .
$$

In order to determine $\tau^{*}$, we know that $\tau \times \ln \delta$ is a straight line from the origin with a slope of $\ln \delta$. We then need to examine the potential convexity of $\ln \left[\frac{\left(1-\delta^{\tau}\right) \times p_{n} \times x_{n} \times \ln \phi}{C \times(1-\delta)}\right] \times\left(1-\delta^{-\tau}\right)$. This is indeed a sufficient condition to decide

Let us define:

$$
y(\tau)=\ln \left[\frac{\left(1-\delta^{\tau}\right) \times p_{n} \times x_{n} \times \ln \phi}{C \times(1-\delta)}\right] \times\left(1-\delta^{-\tau}\right) .
$$


Then,

$$
\frac{\partial y}{\partial \tau}=-\frac{\delta^{\tau} \times \ln \delta}{\left(1-\delta^{\tau}\right)} \times\left(1-\delta^{-\tau}\right)+\ln \left[\frac{\left(1-\delta^{\tau}\right) \times p_{n} \times x_{n} \times \ln \phi}{C \times(1-\delta)}\right] \times \ln \delta \times \delta^{-\tau}
$$

which leads to:

$$
\frac{\partial y}{\partial \tau}=\ln \delta \times\left(-\frac{\delta^{\tau} \times\left(1-\delta^{-\tau}\right)}{\left(1-\delta^{\tau}\right)}+\ln \left[\frac{\left(1-\delta^{\tau}\right) \times p_{n} \times x_{n} \times \ln \phi}{C \times(1-\delta)}\right] \times \delta^{-\tau}\right),
$$

then:

$$
\frac{\partial y}{\partial \tau}=\ln \delta \times\left(\ln \left[\frac{\left(1-\delta^{\tau}\right) \times p_{n} \times x_{n} \times \ln \phi}{C \times(1-\delta)}\right] \times \delta^{-\tau}+\frac{\delta^{\tau} \times\left(\delta^{-\tau}-1\right)}{\left(1-\delta^{\tau}\right)}\right),
$$

and eventually:

$$
\frac{\partial y}{\partial \tau}=\ln \delta \times\left(\ln \left[\frac{\left(1-\delta^{\tau}\right) \times p_{n} \times x_{n} \times \ln \phi}{C \times(1-\delta)}\right] \times \delta^{-\tau}+1\right.
$$

with:

$$
\forall \omega_{1}>0, \frac{\partial y}{\partial \tau}>0
$$

and with:

$$
\forall \tau>0, \frac{\partial^{2} y}{\partial \tau^{2}}>0
$$

We just demonstrated the convexity of the curve.

Hence, due to the convexity of $y(\tau)$, there exists a unique, positive $\tau^{*}$ at which $\partial \omega_{1} / \partial \tau=0$. It is also a maximum, as $\tau \rightarrow \infty$ and $\omega_{1} \rightarrow 0$. Also, $\frac{\partial \omega_{1}}{\partial \tau}>0$ for a sufficiently small $\tau$. In conclusion, since $\tau^{*}$ is unique, it must be a maximum.

We then need to determine $\omega_{1}^{*}$, based on $\tau^{*}$. We know:

$$
\omega_{1}=\ln \left[\frac{\left(1-\delta^{\tau}\right) \times p_{n} \times x_{n} \times \ln \phi}{C \times(1-\delta)}\right] \times \frac{1}{\tau \times \ln \phi},
$$

and we know, at the optimum:

$$
\ln \left[\frac{\left(1-\delta^{\tau^{*}}\right) \times p_{n} \times x_{n} \times \ln \phi}{C \times(1-\delta)}\right] \times\left(1-\delta^{-\tau^{*}}\right)=\tau^{*} \times \ln \delta .
$$

From the previous equation, we obtain:

$$
\tau^{*}=\ln \left[\frac{\left(1-\delta^{\tau^{*}}\right) \times p_{n} \times x_{n} \times \ln \phi}{C \times(1-\delta)}\right] \times \frac{\left(1-\delta^{-\tau^{*}}\right)}{\ln \delta},
$$

then, we end up with: 


$$
\omega_{1}^{*}=\ln \left[\frac{\left(1-\delta^{\tau^{*}}\right) \times p_{n} \times x_{n} \times \ln \phi}{C \times(1-\delta)}\right] \times \frac{1}{\left.\ln \left[\frac{\left(1-\delta^{\tau^{*}}\right) \times p_{n} \times x_{n} \times \ln \phi}{C \times(1-\delta)}\right] \times \frac{\left(1-\delta^{-\tau^{*}}\right)}{\ln \delta}\right) \times \ln \phi},
$$

thus, as a result after simplification:

$$
\omega_{1}^{*}=\frac{\ln \delta}{\left(1-\delta^{-\tau^{*}}\right) \times \ln \phi}=-\frac{\ln \delta}{\left(\delta^{-\tau^{*}}-1\right) \times \ln \phi},
$$

hence, since:

$$
\left(\delta^{-\tau^{*}}-1\right)<=>\frac{1-\delta^{\tau^{*}}}{\delta^{\tau^{*}}}
$$

then:

$$
\omega_{1}^{*}=-\frac{\delta^{\tau^{*}} \times \ln \delta}{\left(1-\delta^{\tau^{*}}\right) \times \ln \phi}=\frac{\delta^{\tau^{*}} \times \ln \delta}{\left(\delta^{\tau^{*}}-1\right) \times \ln \phi} .
$$

Finally, we validate that:

$$
\omega_{1}^{\tau^{*}}>0, \text { since } 0<\delta<1 \text { and } \phi>1 \text {. }
$$

Q.E.D. 